\title{
Usage Frequency of Product Configuration Systems Relative to Integrations and Fields of Application
}

Shafiee, Sara; Kristjansdottir, Katrin; Hvam, Lars; Battistello, Loris; Sandrin, E.

Published in:

Proceedings of the 2017 IEEE International Conference on Industrial Engineering and Engineering Management (IEEM)

Link to article, DOI:

10.1109/IEEM.2017.8289882

Publication date:

2017

Document Version

Peer reviewed version

Link back to DTU Orbit

Citation (APA):

Shafiee, S., Kristjansdottir, K., Hvam, L., Battistello, L., \& Sandrin, E. (2017). Usage Frequency of Product Configuration Systems Relative to Integrations and Fields of Application. In Proceedings of the 2017 IEEE International Conference on Industrial Engineering and Engineering Management (IEEM) (pp. 211-214). IEEE. https://doi.org/10.1109/IEEM.2017.8289882

\section{General rights}

Copyright and moral rights for the publications made accessible in the public portal are retained by the authors and/or other copyright owners and it is a condition of accessing publications that users recognise and abide by the legal requirements associated with these rights.

- Users may download and print one copy of any publication from the public portal for the purpose of private study or research.

- You may not further distribute the material or use it for any profit-making activity or commercial gain

- You may freely distribute the URL identifying the publication in the public portal 


\title{
Usage Frequency of Product Configuration Systems Relative to Integrations and Fields of Application
}

\author{
S. Shafiee ${ }^{1}$, K. Kristjansdottir ${ }^{2}$, L. Hvam ${ }^{2}$, L. Battistello ${ }^{3}$, E. Sandrin ${ }^{3}$ \\ ${ }^{1}$ Department of Mechanical Engineering, Technical University of Denmark, Lyngby, Denmark \\ ${ }^{2}$ Department of Management Engineering, Technical University of Denmark, Lyngby, Denmark \\ ${ }^{3}$ Department of Management and Engineering, University of Padova, Stradella S. Nicola, 3, 36100 Vicenza, Italy

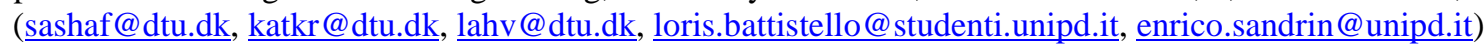

\begin{abstract}
Product Configuration Systems (PCS) are automatic solutions that can support and facilitate the sales and engineering processes. PCSs have recently attracted increased attention both from the researches and practitioners. There are variety of challenges reported in the literature as consequences of using $\mathrm{PCS}$, which reduces the usage frequency of the system. To address those challenges, IT integrations can be an effective solution to reduce the number of manual tasks and complexity inside PCSs and make PCSs more user friendly. However, the influence of integrating PCS to different IT systems on usage frequency has not been addressed in the literature. This paper aims to study the relationship of PCS usage frequency in terms of (1) different application area of the PCSs, and (2) integrations to different IT systems. The research method adopted in the paper is survey-based conducted in one company where the unit of analysis is operating PCS.
\end{abstract}

Keywords - Product Configuration System (PCS), frequency, integration, field of application

\section{INTRODUCTION}

Product Configuration Systems (PCS) are attracting increased attention as they support the tasks involved in the customer-oriented business processes related to the specification of products [1]. PCSs enable companies to develop product alternatives to facilitate the sales and production processes [2] by incorporating information about product features, product structure, production processes, costs and prices [3]. Widely used in various industries, PCS can bring substantial benefits, such as shorter lead times for generating quotations, fewer errors, increased ability to meet customers' requirements regarding product functionality, the use of fewer resources, optimized product designs, less routine work and improved on-time delivery [4]-[7]. There are, however, challenges reported regarding planning, developing, and maintaining PCSs which require management and IT solutions. PCS can be applied to support the decision-making processes in the sales and engineering phases of a product, where the most important decisions regarding product features and product costs are made [1].

PCS can support different processes at the companies such as sales, design /engineering, production. There are also studies analysing integration and their importance for PCSs. However, there is no study on the impact of types of PCSs and integrations on usage frequency of PCS. This is an important topic as it provides further insight into the factors that can increase usages frequency of PCS. The frequency measure how many time PCS has been used by users over a specific period (per year). This paper aims to capture the research opportunity by analysing the following research questions (RQs):

$\boldsymbol{R} \boldsymbol{Q}$. 1: Which types (sales or engineering) of PCS are used more frequently than others?

RQ.2: What is the influence of integration with other IT systems on usage frequency of PCSs?

To answers to the RQs, a survey followed with interviews was conducted. The results presented in this paper are preliminary as this is an ongoing study. Therefore, the results are only based on one company where the unit of analysis is based on operating PCS. The gathered results are analysed per year.

The structure of the paper is as follows. Chapter II discusses the relevant literature, and Chapter III explains the research method. Chapter IV presents the results of the research, and Chapter $\mathrm{V}$ discusses the results in relation to the RQs and presents the conclusion.

\section{LITERATURE BACKGROUND}

\section{A. Sales and engineering PCSs}

PCSs support the product configuration process including of a set of activities from gathering the raw data to maintaining the system [8][3]. The PCSs can be divided into sales and technical configuration processes [9]. The difference between the PCS outputs based on the level of detail of the output can determine the PCS differences and divide them [10]. The sales configuration process is concerned with identifying products that fulfil customers' needs and determining the main characteristics of the products in a high level of abstraction [9], [10]. The technical engineering configuration process, on the other hand, is concerned with generating documentation for the products based on the input gathered during the sales phase [9], [10]. Another dimension of the configuration process is production configuration [11], which can be used as an internal tool to support the company's employees during the product configuration process [12]. 


\section{B. PCSs in integration with other IT systems}

Tallon et al. [13] point out that any positive impact of IT comes from its ability to coordinate value adding activities. A linkage between integrative IT and supply chain is a key aspect of supply chain integration. Stroeken [14] examines the link between IT and supply chain innovation in six industry sectors in order to show the importance of IT to develop the process oriented structure of the supply chain needed for the integration [14]. Tiihonen and Felfernig [15] provide an overview of the existing approaches specifically to the integrations of PCS and recommendation technology.

PCSs can be applied as standalone software, as well as data-integrative and application-integrative systems [12]. Data-integrative PCSs can be used to avoid data redundancies and application-integrative PCSs allow for communication across different applications (e.g. CAD drawings can be generated from the output of the PCS) [12]. In terms of data integration for PCSs, common sources for master data can be found in Enterprise resource planning (ERP) systems that often define a production-relevant view of the material. This is required for the assembly process, product data management (PDM) and product lifecycle management (PLM) systems, which are used to maintain production relevant data. Finally, product information management (PIM) systems are used to maintain sales-relevant data [16]. Because of organizational reasons or confidentiality issues, the complete PCS logic in one centralized knowledge base is undesirable [6]. This means that the integration of different expert systems handling different tasks is required which requires an integration and harmonization process during the setup of the supply chain [6].

Finally, PCS can be integrated into suppliers systems to retrieve the required data from the configuration processes [6]. A number of studies have explored the hypothesis that "the higher the degree of integration across the supply chain, the better a firm performs" [17]-[22]. Having PCS integrated across supply chains (e.g., where information is retrieved directly from suppliers in the configuration process) has proven to significantly increase the accuracy of the specifications of highly engineered products and reduce complexity [23].

\section{METHODOLOGY}

In this chapter the research method will be elaborated. A survey is conducted followed with interviews which leads to get more in depth knowledge. The results presented in this article are part of an ongoing study of a larger survey.

The result presented in the paper is based on answers from one company. This is thought to provide a valuable insight as by studying one company an in-depth knowledge about the configuration setup could be accessed. More case will be added in the future which will provide a cross functional comparison for the further study.

The company introduced in the study has utilized PCSs since 1999 and has currently 159 operational PCSs, which support the specification processes in the sales and the engineering at the company. The company therefore has an extensive experience from working with PCSs and knowledge to be shared.

The unit of analysis is based on operational PCSs at the company. A PCS is defined as model based expert system with it is own knowledge base and inference engine. The frequency is then presented on yearly bases. In order to collect data, first a questionnaire was developed and revised several times by the research team in order to check consistency. In the next phase, the questioner was emailed to the company and an interview with the company was setup. Based on the first interview it was decided that the research team would work with a project manager from the configuration team for two days to gather and evaluate the required data. The data was gathered from internals systems at the company and verified by the project manager to check constancy.

The data was then analyzed in Microsoft Excel in relations to the RQs. The PCS were grouped according to specification processes they supported, or into sales, sales and engineering, and engineering. A limitation of the data is that the majority of the PCSs are used to support the engineering processes (75\%), and sales and engineering processes (19\%) while there are few PCSs used to support only sales processes (3\%) and finally PCSs used to support other processes are $(2 \%)$. Nevertheless, the results presented are thought to provide valuable insight into the complexity of PCSs while further data gathering is planned to support the findings. In relation to data of the integrated IT systems to the PCSs, a regrouping was also done. In that sense where there was more than one integration to the PCSs they were listed under combination of integrations, which included the following combinations: (1) CAD and ERP, (2) CAD, ERP and calculation systems, and finally (3) ERP and calculation system.

\section{RESULTS}

In this chapter the main result from the survey are presented aligned with both the RQs introduce in the paper.

The first section elaborates on different types of the PCSs used in the sales, both in sales and engineering processes and finally only in the engineering processes. The relation between the PCS usage frequency and their fields of application is analyzed (RQ 1). The second section elaborates the usage frequency of the PCSs influenced by integrations to other IT systems (RQ 2). The integrations include, ERP, CAD, calculations systems, where there are few PCSs that have integrations to other systems and few that have no integrations. The results presented are based on data from 159 PCSs that are used within on company as explained in Chapter III. 
A. Frequency measurement in relation to the type of PCSS

This chapter analyses different types of PCS and studies how frequent they were used at the company. Figure 1 shows the percentage of different types of PCSs at the case company.

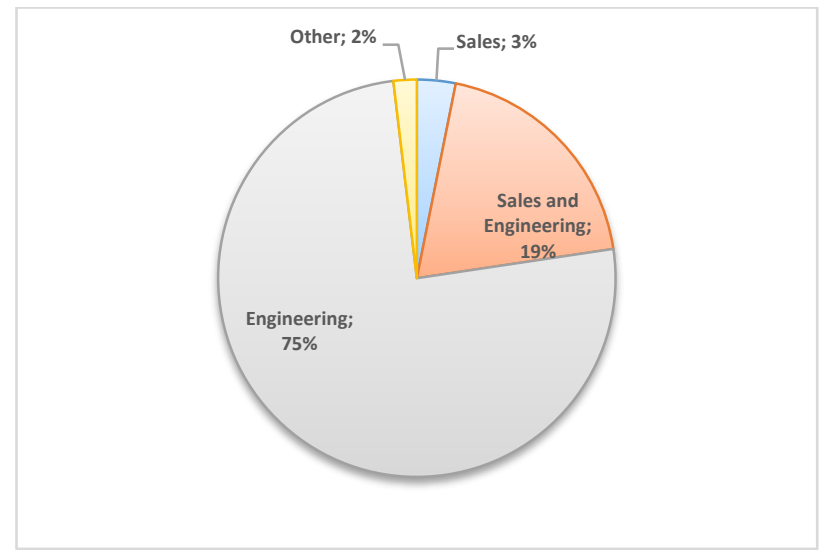

Fig. 1. Percentage of types of PCSs in use at the company

As can be seen in Figure 1 there are not many PCSs that are only used to support the sales processes or only $5 \%$, while $19 \%$ of the PCSs are used to support both sales and engineering, $75 \%$ of the PCSs are used to support only engineering and $2 \%$ are used for other activities.

Figure 2 illustrates the relations between frequency and types of PCS at the company. As it can be seen the frequency of usage is highest for engineering and sales PCSs and it is reducing when it moves towards sales PCS.

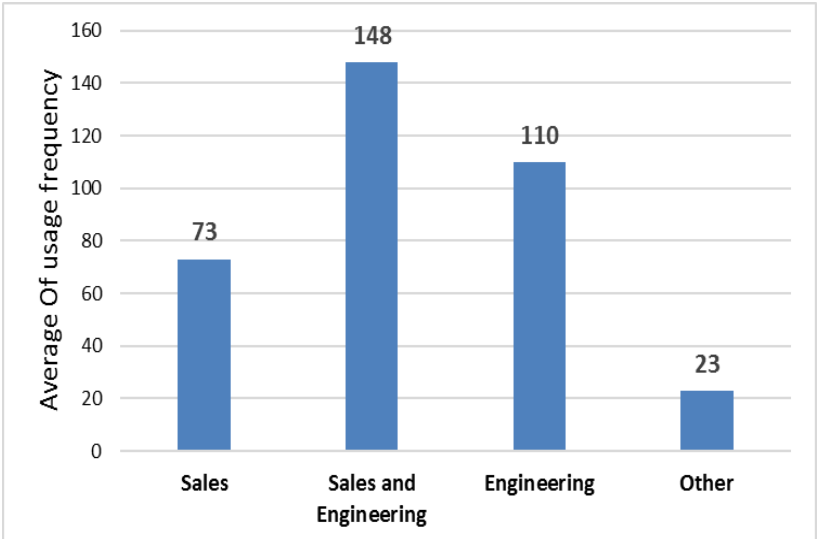

Fig. 2. Usage frequency of the PCS used to support the different activities at the company.

\section{B. Frequency measurement in relation to the IT integration in PCS}

The integrations the PCSs had at the company included the following IT systems: ERP, CAD, calculation systems and in few case other systems. $4 \%$ of the PCS did not have any integration, while $70 \%$ of the PCS were integrated to one of the above mentioned systems and $26 \%$ were integrated to one or more of the systems. In Figure 3 the combination of the different integration setup is shown.

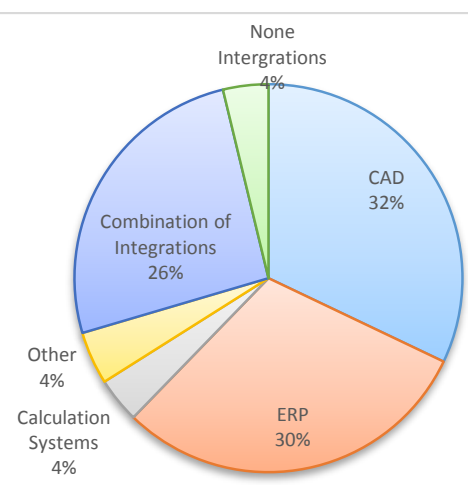

Fig. 3. Percentages of integrations of the PCS with different IT systems used at the company.

The usage frequency of PCS with different types and combinations of integrations is shown in Figure 4. As it is illustrated in the Figure 4, the most frequently used PCS in terms of integrations with other IT systems is the combined IT systems of integrations. This means that PCSs are more frequently used if there is integration to multiple IT systems. Moreover, ERP system integration with PCSs is illustrated the most important integration at the company as its usage frequency average seems to be very high.

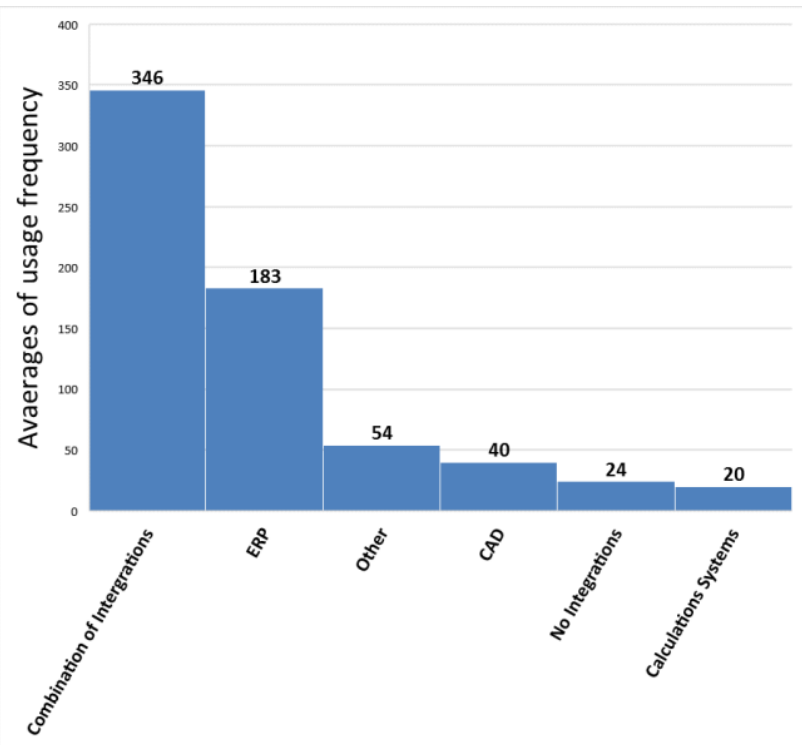

Fig. 4. Average usage frequency of PCSs based on different types of integrations to different IT systems used at the company per year.

\section{DISCUSSION AND CONCLUSION}

This study provides insights into usage frequency of PCSs, which is based on trust and popularity among users of the system. The paper aims to analyze the influence of different types of PCS and different types of integration in 
PCSs on the usage frequency of the PCSs.

RQ 1 aims to identify the most frequent used PCS based on their application at the case company. Based on the results, the combined engineering and sales PCSs seem to be more frequently in use in comparison with engineering and sales PCSs. The reason is that they are detailed enough to be used for engineering purpose and at the same time they can cover the sales people requirements. That means that there are both sales and engineering sections using the system which will increase the number of users and usage frequency of the system. The second highest usage frequency belongs to engineering PCSs. The engineering PCSs provide more detailed documents for the users, which will lead to increased user frequency and higher tendency in using them. Moreover, the sales PCSs which are in used only in sales and presales process are the simple PCSs but they are less used in the company. The reason could be that less detailed and complex PCSs in the sales phase generate less documents for the business.

RQ 2 aims to provide more knowledge about the influence of different integrations on the usage frequency of PCSs. The PCSs with combination of integration to other IT systems are more frequently used. The higher number of IT integration can provide detailed PCSs which could generate detailed outputs for users. On the other hand, high numbers of integration to relevant IT expert systems increase the level of accuracy of outputs. However, ERP systems integration has the highest usage frequency when there is only integration with one IT system. This shows importance of knowledge sharing between PCSs and ERP systems. Besides, ERP systems contain knowledge about different dimensions of the product and customers which are needed in all of the configuration processes. CAD systems seems to have the second highest importance as CAD systems increase the number of outputs such as $2 \mathrm{D}$ and $3 \mathrm{D}$ figures with no influence on data accuracy.

This paper does therefore not analyze all the different types of integrations. Further study will therefore be focused and gathering data from companies that have more variety of IT systems the PCSs are integrated to. Besides, the result presented in the paper is based on answers from one case company. This is thought to provide a valuable insight as by studying one company an in-depth knowledge about the PCS setup could be accessed. More case will be added in the future which will provide a cross functional comparison for the further study.

\section{REFERENCES}

[1] L. Hvam, N. H. Mortensen, and J. Riis, Product customization. Berlin Heidelberg: Springer, 2008.

[2] A. Felfernig, L. Hotz, C. Bagley, and J. Tiihonen, Knowledge-Based Configuration From Research to Business Cases. Morgan Kaufman, 2014.
[3] C. Forza and F. Salvador, Product information management for mass customization: connecting customer, front-office and back-office for fast and efficient customization. New York: Palgrave Macmillan, 2007.

[4] L. Hvam, S. Pape, and M. K. Nielsen, "Improving the quotation process with product configuration," Comput. Ind., vol. 57, no. 7, pp. 607-621, Sep. 2006.

[5] T. D. Petersen, "Product Configuration in ETO Companies," in Mass customization information systems in business, 2007, pp. 59-76.

[6] L. Ardissono et al., "A Framework for the Development of Personalized, Distributed Web-Based Configuration Systems," AI Mag., vol. 24, no. 3, p. 93, 2003.

[7] F. Salvador and C. Forza, "Configuring products to address the customization-responsiveness squeeze: A survey of management issues and opportunities," Int. J. Prod. Econ., vol. 91, no. 3, pp. 273-291, Oct. 2004.

[8] C. Forza and F. Salvador, "Managing for variety in the order acquisition and fulfilment process: The contribution of product configuration systems," Int. J. Prod. Econ., vol. 76, no. 1, pp. 87-98, Mar. 2002.

[9] C. Forza and F. Salvador, "Application support to product variety management," Int. J. Prod. Res., vol. 46, no. 3, pp. 817-836, Feb. 2008.

[10] A. Haug, L. Hvam, and N. H. Mortensen, "The impact of product configurators on lead times in engineeringoriented companies," Artif. Intell. Eng. Des. Anal. Manuf., vol. 25, no. 2, pp. 197-206, Apr. 2011.

[11] L. L. Zhang, E. Vareilles, and M. Aldanondo, "Generic bill of functions, materials, and operations for SAP2 configuration," Int. J. Prod. Res., vol. 51, no. 2, pp. 465-478, 2013.

[12] T. Blecker, N. Abdelkafi, G. Kreutler, and G. Friedrich, "Product configuration systems: state of the art, conceptualization and extensions," in Proceedings of the Eight Maghrebian Conference on Software Engineering (MCSEAI 2004), 2004, pp. 25-36.

[13] P. Tallon and K. Kraemer, "Multidimensional Assessment of the Contribution of Information Technology to Firm Performance," Cent. Res. Inf. Technol. Organ., 1996.

[14] J. Stroeken, "Information technology, innovation and supply chain structure," Int. J. Serv. Technol. Manag. vol. 2, no. 3-4, pp. 269-288, 2001.

[15] J. Tiihonen and a. Felfernig, "Towards recommending configurable offerings," Int. J. Mass Cust., vol. 3, no. 4, p. 389, 2010.

[16] T. Krebs, "encoway," in Knowledge-based configuration: From research to business cases, A. Felfernig, L. Hotz, C. Bagley, and J. Tihonen, Eds. Morgan Kaufman, 2014, pp. 271-279.

[17] G. C. Stevens, "Integrating the Supply Chain," Int. J. Phys. Distrib. Mater. Manag., vol. 19, no. 8, pp. 3-8, 1989.

[18] R. Metters, "Quantifying the bullwhip effect in supply chains," J. Oper. Manag., vol. 15, no. 2, pp. 89-100, 1997.

[19] H. L. Lee, V. Padmanabhan, and S. Whang, "Information Distortion in a Supply Chain: The Bullwhip Effect," Manage. Sci., vol. 43, no. 4, pp. 546558, 1997.

[20] M. Frohlich and R. T. Westbrook, "Arcs of integration: an international study of supply chain strategies," $J$. 
Oper. Manag., vol. 19, no. 2, pp. 185-200, 2001.

[21] P. Hines et al., "Value Stream Management," Int. J. Logist. Manag., vol. 9, no. 1, pp. 25-42, 1998.

[22] R. Johnston and P. R. Lawrence, "Beyond Vertical Integration -- The Rise of the Value-Adding Partnership," Harv. Bus. Rev., vol. 66, no. 4, p. 94, 1988.

[23] K. Kristjansdottir, "Improved Performance and Quality of Configurators by Receiving Real-Time Information from Suppliers," in Configuration Workshop, 2016. 